\title{
$\mathrm{SiC}$ 材料の表面加工と電気的作用
}

\author{
江龍 修・田中 弥生 \\ 名古屋工業大学 大学院機能工学専攻 俨466-8555 愛知県名古屋市昭和区御器所町 \\ （2013 年 10 月 15 日受付；2013 年 11 月 28 日掲載決定）
}

Surface Processing of $\mathrm{SiC}$ and Relations with the Electrical Properties

Osamu Eryu and Yayoi TANaka

Nagoya Institute of Technology, Gokiso-cho, Showa-ku, Nagoya, Aichi 466-8555

(Received October 15, 2013 ; Accepted November 28, 2013)

\begin{abstract}
We made an off-axis surface of SiC with the chemical-mechanical polishing (CMP) method to examine the influence of an atomic step on the electronic properties. It became clear that processing pressure had the threshold in the electric field that let the removal of the atom accelerate using the abrasive of the piezoelectric particles. The electric charge distribution of the $\mathrm{SiC}$ surface affects the removal rate of $\mathrm{SiC}$. The conductive atomic force microscopy (CAFM) method is effective technique to examine processing mechanism of the materials surface.
\end{abstract}

KEYWORDS : SiC, dielectric abrasive, conductive atomic force microscopy

\section{1.は じめに}

炭化ケイ素半導体 $(\mathrm{SiC})$ は主に周波数変換やスイッ チングなど，パワーデバイスと呼ばれる分野で，その利 用が期待されている。パワーデバイスで求められる一つ の要素は, ロスなく電力を操作することである。この操 作時の省エネルギー化は, 特に, 大電力制御において効 果が大きい1)。小さな電力を制御して，大きな省エネ効 果を生むケースにおいては, 今後も主力材料は量産効果 が高いシリコン半導体 $(\mathrm{Si})$ である。さらに, 高速・高 周波領域においては, 急速に量産化技術が進化してきて いる，窒化ガリウム半導体 $(\mathrm{GaN})$ が主役となりつつあ $る^{2,3)}$ 。一方, 新幹線や大型土木用機械, 大型のマシニ ングセンタなど, 我が国が得意な分野におけるパワート レイン制御において, 精密制御やトルクの向上が求めら れる部分において, $\mathrm{SiC}$ は主力材料になる潜在力を持 つ。それは単一素子で大電力を制御可能なためであ る4)。さらには大きな電力制御が, 可聴周波数を超えた トランジス夕動作が可能となるため ${ }^{5)}$, ハイブリッド車 や電気自動車の走行時にデバイスノイズが聞こえなくな

E-mail : eryu.osamu@nitech.ac.jp
る快適性が得られる。一方で, $1.2 \mathrm{kV}, 1 \mathrm{kA}$ でのスイッ チング時が求められるなど, 電磁妨害（EMI : Electro Magnetic Interference）が予想されるため, 対応する周辺 回路素子の開発や電磁波シールド技術が新たに求められ るようになってきている。これはまた， $\mathrm{SiC}$ デバイスが 市場に出回り始めたことも意味する。このように大電力 動作が $\mathrm{SiC}$ のデバイス材料として求められることから, 成長インゴットから基板化する際に生じる結晶欠陥は致 命的となる。理想的には Si と同様に, 研磨欠陥を化学 薬品によってエッチングして取りのぞくことであるが, $\mathrm{SiC}$ は耐酸・アルカリ性がきわめて高く, 加工欠陥を工 ッチングにて取り除くことは困難である。優れた事例と して白金の触媒作用を活用し，フッ化水素を反応剂とし て加工欠陥を除去する手法が報告されており，発展が期 待される6,7)。ここでは, $\mathrm{SiC}$ などのイオン結合性を有す る多元素系材料の, デバイス化に向けた加工技術開発に おける着眼点を述べる。加工時に $\mathrm{SiC}$ に掛かる圧力が $\mathrm{SiC}$ 内部に電解を発生させ, それが加工に影響を与えて いる結果を示す。さらに, 平坦化加工によって得られ た, 多元素系材料の表面電子特性について述べる。原子 ステップが得られる程度に加工したステップエッジに表 出する原子の電子的特性が, 表面のマクロな電気的特性 
に影響を与える結果を示す。

\section{2. 研磨加工における圧力効果}

\section{1 加工条件}

本節で用いた基板は，市販されている $4 \mathrm{H}-\mathrm{n}$ 型 $\mathrm{SiC}$ で, キャリア濃度は室温でのドナー濃度とアクセプ夕濃 度の差は $N_{D}-N_{A} \cong 7 \times 10^{17} \mathrm{~cm}^{-3}$ である。ここでは可能 な限り(0001) 面に近い C 面を用いている。(0001) 面か らのオフ角度は 0.05 度以内であることを, AFMにより 確認している。ここでは, 研磨加工時の圧力効果を評価 するために, 圧電体材料を研磨砥粒とした。 $\mathrm{SiC}$ の研磨 加工プロセスは, 未だスタンダードな加工法は確立され て扔らず，研磨に用いる砥粒と $\mathrm{SiC}$ との反応状態を調 ベることで, デバイス基板として用いる際に最適化され た表面が得られると考える。そのため, 多く形状形成過 程に用いられるダイヤモンド研粒ではなく, 加工加重と 研磨量との関係を推測するために圧電体材料を用いた。 用いた圧電体材料と物性定数, および諸条件を Table 1 に示す。圧電定数と比誘電率との比 $\mathrm{d} / \varepsilon$ は, 歪と, それ に伴い生じる電界との関係を示すものであり, 数值が大 きいほど, 歪に対する電界強度が大きくなる。この值 と, 加工量との関連を調べることで, 材料加工に扔ける 表面の電気的作用について検討する。

\section{2 加工能率圧力依存性}

Fig. 1 に研磨砥粒として $\mathrm{BaTiO}_{3}$ を用いた場合の, $\mathrm{SiC}$ の C 面に扔ける加工圧力と加工能率との関係を示す。 加工圧力が約 $850 \mathrm{~g} / \mathrm{cm}^{2}$ までは, $75 \mathrm{~nm} / \mathrm{h}$ の加工能率が 得られている。一方で $850 \mathrm{~g} / \mathrm{cm}^{2}$ を超える圧力を加える と, 加工能率が急激に増加していることがわかる。これ は, 圧電材料が発生させる $\mathrm{SiC}$ 表面に及ぼす電界強度 と $\mathrm{SiC}$ 表面からの原子の脱離とに閥値が存在している ことを示していると考える。

次に Fig. 2 に, 3 種類の砥粒を用い, $\mathrm{BaTiO}_{3}$ を用いた 場合に加工能率が一定と考えられる圧力領域と, 加工能 率が増加した圧力領域での比較を行った結果を示す。図 の棒グラフに用いた砥粒を示す。Fig. 2 より, Table 1 に 示した $\mathrm{d} / \varepsilon$ の值が大きい砥粒において, 加工能率が高く なっていることがわかる。 $\mathrm{SiC}$ 表面への酸素イオンの供

Table 1. Abrasives and physical constant.

\begin{tabular}{ccccc}
\hline Abrasives & $\begin{array}{c}\text { Dielectric } \\
\text { constant } \\
\varepsilon\end{array}$ & $\begin{array}{c}\text { Piezoelectric } \\
\text { constant d }\end{array}$ & $\mathrm{d} / \varepsilon$ & $\begin{array}{c}\text { Mean } \\
\text { diameter } \\
(\mu \mathrm{m})\end{array}$ \\
\hline $\mathrm{BaTiO}_{3}$ & 2000 & 200 & 0.1 & 0.66 \\
$\mathrm{SrTiO}_{3}$ & 200 & 100 & 0.5 & 0.57 \\
$\mathrm{MgTiO}_{3}$ & 15 & 250 & 16.7 & 0.95 \\
\hline
\end{tabular}

給が加工能率と関係していることが知られており ${ }^{3)}$, 表 面に吸着している酸素イオンに及ぼす圧電材料が発生す る電界との相互作用によって加工が進行すると考える。 本結果は, イオン結合性を有する材料の研磨加工におい て, 表面に与える電気的作用が加工能率に影響を与える ことを示していると考える。今後, 共有結合性結晶にお いて圧電体による研磨加工を実施し, 本研究の検証を行 っていく。

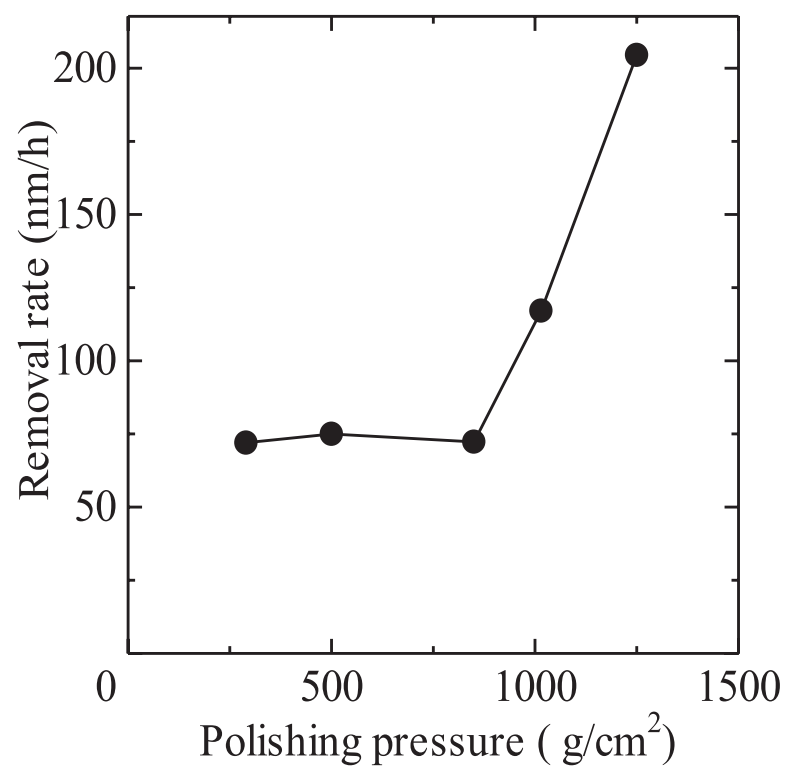

Fig. 1. Relations with polishing pressure and removal rate with $\mathrm{BaTiO}_{3}$ ablasive.

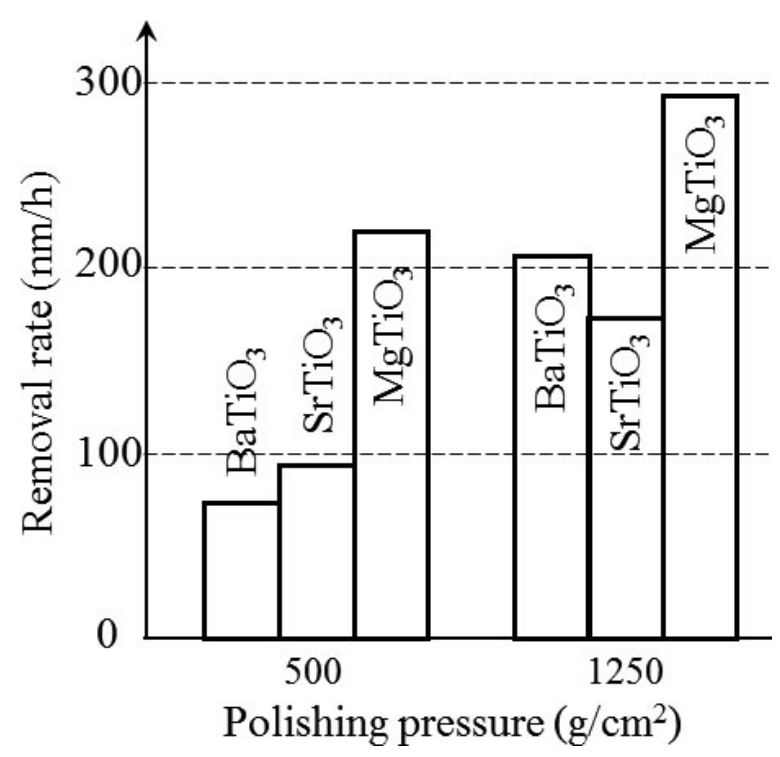

Fig. 2. Relations with abrasives and removal rate. 


\section{3. 加工表面の電子的観察}

\section{1 評価手法}

前節において, 砥粒が発生する圧電作用と加工能率と の関係について議論した。本節では加工によって得られ る $\mathrm{SiC}$ 表面の原子ステップの電気的特性を導電性 $\mathrm{AFM}$ (Conductive Atomic Force Microscopy : CAFM) により調 べた結果を述べる。Fig. 3 に SiC 表面のテラス幅と CAFM 探針径との関係を示す。オン面加工表面におい ては, ステップ間のテラス幅は, AFM 観察によって大 略 $250 \mathrm{~nm}$ であることがわかっている ${ }^{8)}$ 。一方, 3.5 度の オフセットを取って研磨加工した場合には, テラス幅は 大略 $4 \mathrm{~nm}$ となると見積もることができる。 Si 原子と C 原子の電気陰性度を比較した場合, $\mathrm{C}$ 原子が大きく, し たがって, SiCのイオン結合性において, 負性の電荷分 布は $\mathrm{C}$ 原子に偏ることになる。これにより, $\mathrm{SiC}$ の $\mathrm{Si}$ 面を加工した場合, 原子ステップエッジには C 原子が 露出することになる。CAFMにおいて用いたダイヤモ ンド探針は, $\mathrm{SiC}$ の $\mathrm{Si}$ 面に対しては電子的なバリア性 を示し，一方でC 面においては，そのバリアが低い9 したがって, 表面の原子ステップ密度と表面の負性電荷 分布との関係を，ダイヤモンド探針を用いた CAFMに よって，直接的に観測できると考えた。

\section{2 CAFM 測定結果}

Fig. 4 に電界の方向を, $\mathrm{SiC}$ 基板からダイヤモンド探 針側にとり, $\mathrm{SiC}$ 基板に対するダイヤモンド探針側の負 バイアスを大きくしていった際の, 基板からダイヤモン ド探針に流れる電流との関係を示している。基板をゼロ 電位（アース電位）に取っていることから, グラフの横 軸を, 右から左に向かって負の側に大きくなっている図 としている。縦軸は探針と基板間に流れる電流の大きさ を取っている。Fig. 4 によれば, 基板のオフセット角度 が大きい場合において, 電流值が大きくなっていること がわかる。この結果は, 基板表面に露出する $\mathrm{C}$ 原子が 多い場合に，電流值が大きくなっていることを示してい ると考える。 $\mathrm{SiC}$ 基板の研磨加工において, Si 面は C 面に比べて加工能率が低いこと, および，オフセット角 度が大きくなるに従い, 加工能率が高くなることがわか っている9)。本测定結果は, ステップ端に存在する C 原 子が電気的な反応起点となって, 加工が進行していくこ とを示していると考える。今後，オン面基板を用いて， ステップとテラスにおける電気的特性を精密にマッピン グしていくことで, ステップ端の電子的な特性を明らか にしていきたい。

前節の圧電体を用いた加工結果と合わせて考えると, 研磨時の加工圧力は, 材料表面に存在する電荷分布を変

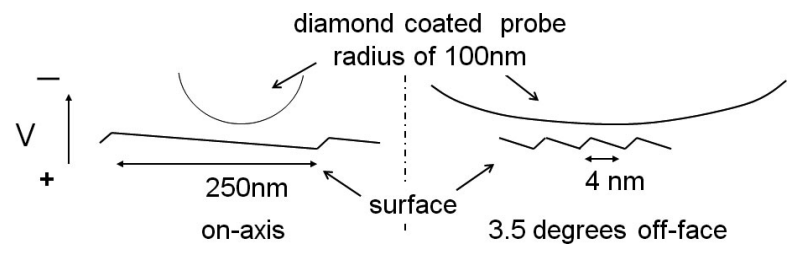

Fig. 3. Principles of the conductive atomic force microscopy.

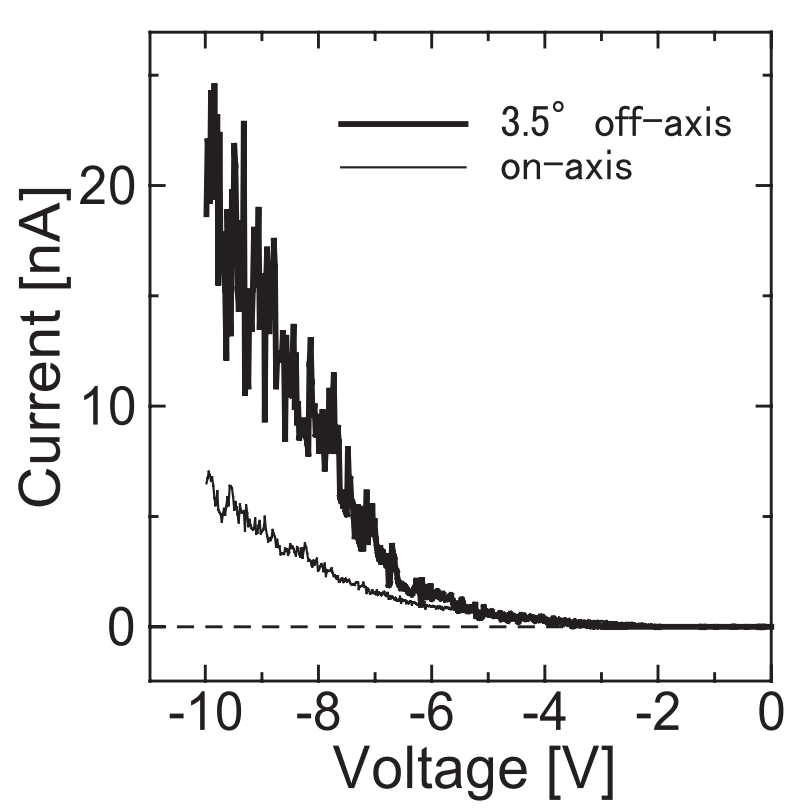

Fig. 4. Current measurements between AFM prove and SiC.

化させる働きをすることも考えられ, 加工圧力は研磨加 工時の機械的除去力を高めるのみではなく，被加工物表 面の電子分布を変化させることに影響を与えると考えら れる。したがって, $\mathrm{SiC}$ 等の結合にイオン性を有する材 料の研磨加工においては, 材料表面における機械的歪に よる電荷の分布までを考慮し, 加工圧力を検討する必要 があると考える。

\section{4. を め}

我々は, 圧電体材料を研磨砥粒として用いることで, $\mathrm{SiC}$ 表面に存在する電荷の分布が加工能率に影響を与え ることを示した。導電性 AFM を用いることで, 被加工 物の表面電荷分布を測定できる可能性を示した。両手法 により, 加工時に表面近傍に生じる電界が, 加工特性に 強く作用していることを示す結果を得た。今後, 電気的 作用を積極的に取り入れた加工法が，イオン結合性を有 する材料加工の研究に取り入れられていくことを期待す る。 


\section{謝辞}

本研究は豊田工業大学 吉村雅満教授, および, 株式 会社フジミインコーポレーテッド 永利一幸氏の協力を 得た。ここに謝意を表する。

\section{文献}

1) K. Kyuma, extended abstract : ICSCRM 2013 Mo-PL-1, ICSCRM 2013, Sept. 29-Oct. 4, 2013, Miyazaki, Japan.

2) D. Marcon, B. De Jaeger, S. Halder, N. Vranckx, G. Mannaert, M. Van Hove and S. Decoutere: IEEE Transactions on Semiconductor Manufacturing 26, 361 (2013).

3) H.H. Liu, H.Y. Lin, C. Liao and J. Chyi : ECS J. Solid State Sci. Technol. 2, N3001 (2013).
4) J. Biela, Member, M. Schweizer and S. Waffler : IEEE transactions on industrial electronics 58, 2872 (2011).

5) 鶴田和弘: デンソーテクニカルレビュー 16, 90 (2011).

6) H. Hara, Y. Sano, H. Mimura, K. Arima, A. Kubota, K. Yagi, J. Murata and K. Yamauchi : J. Electron. Mater. 35, L11 (2006).

7) H. Hara, Y. Sano, H. Mimura, K. Arima, A. Kubota, K. Yagi, J. Murata and K. Yamauchi : Mater. Sci. Forum 556-557, 749 (2007).

8) K. Hotta, K. Hirose, Y. Tanaka, K. Kawata and O. Eryu : Mater. Sci. Forum 600-603, 823 (2009).

9) Y. Tanaka, T. Kanda, K. Nagatoshi, M. Yoshimura and O. Eryu : Mater. Sci. Forum 717-720, 569 (2012). 